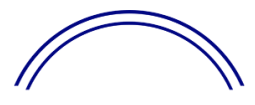

\title{
The Impact of the Illusory Truth Effect and Location of Testimony in Juror Deliberations
}

\author{
Alexandrea Johnston, ${ }^{1}$ Daniel Ambrosini, ${ }^{2}$ Bruno Losier ${ }^{2,3}$ \\ ${ }^{1}$ Munk School of Global Affairs and Public Policy, University of Toronto, Toronto, Canada; ${ }^{2}$ Department of Psych- \\ iatry and Behavioural Neurosciences, McMaster University, Hamilton, Canada; ${ }^{3}$ Forensic Psychiatry Program, St. \\ Joseph's Healthcare Hamilton, Hamilton, Canada
}

\begin{abstract}
The illusory truth effect (ITE) is the tendency to believe false information as being accurate after it has been presented repeatedly over time. ITE has been shown to hold true in many different contexts; however, there have been no studies that examine the influence of ITE in jurors' deliberation. Given the importance of weighing legally relevant facts in the decision-making process, and the potential influence of ITE, this study examined whether the repetition of key evidence in testimony matters in this context. This study also examined whether critical information would be influenced by the location of ITE. In that context, jurors may process critical information differently when introducing ITE early (i.e., primacy effect) or later (i.e., recency effect) in the vignette of a murder case. To examine this effect, 100 participants were recruited and asked to read a vignette where pertinent evidence related to a murder was strategically repeated throughout the case narrative. Participants were assigned to one of four groups: control; ITE throughout vignette; ITE at the beginning of vignette; and ITE at the end of vignette. After reading the vignette, participants were asked to complete a short questionnaire and provide a final decision about various aspects of the case. Results revealed that repetition of pertinent evidence matters. The placement of evidence also has the potential to influence jurors' perceptions of certain case relevant details. These findings suggest that within a sensitive legal context, such as jurors weighing evidence of an accused's culpability, ITE could alter one's perception of the facts.
\end{abstract}

Keywords: illusory truth effect, ITE, testimony, juror deliberations, primacy effect, recency effect

In recent years, trial lawyers have adopted the use of psychological principles and processes in the hope of better understanding and influencing the jury deliberation process [1]. Although it is difficult to know the details about real juror deliberations, mock juries allow us to understand how jurors make decisions and possible techniques to persuade them. Studies have shown that a lawyer's language, appearance, and presentation of evidence in court can unconsciously persuade jurors' perception of a case [1]. These findings have been used by jury consulting companies to strategically plan high-profile trials that can assist in persuading jurors.

Furthermore, when jurors assemble to deliberate, a normative social influence, defined as the "influence to conform with the positive expectations of another," has been shown to impact jury deliberation and a strong persuasion effect on decision-making has been documented [2].

Outside the context of jury deliberation, individuals' decision-making has been shown to 
be influenced by a persuasive phenomenon called the illusory truth effect (ITE), which was first reported in 1977 [3]. This phenomenon asserts that even inaccurate information, written or verbal, can become credible to the audience if the information is repeated enough [4]. Although ITE has been shown in many different contexts, in high-stakes situations, such as jurors' deliberations, it remains unexplored.

\section{What is it about ITE that turns the implausible into plausible?}

ITE is believed to be driven by "processing fluency," a psychological phenomenon that underscores the ease in which individuals comprehend statements. As repetition makes statements easier to process, individuals begin to believe the statements are more likely to be true and therefore assign it a higher salient value [5]. Gigerenzer and Gaissmaier [6] showed the importance of salience in this context, specifically that when one option is recognized faster than another, it is given a higher value in the decision-making process. Hence, in this framework, repeating statements will increase the ease of processing and understanding of information that has the added benefit of giving the statement more credibility than may be justified [5]. Moreover, Unkelback \& Rom [7] purported ITE to be a robust phenomenon with lasting impacts ranging minutes, weeks, and months. DiFonzo and colleagues [8] used a set of clever experiments to clearly show that plausible statements of unknown truth, which were repeated to naive participants, were rated as more likely to be true than nonrepeated statements. Thus, the nature, source, or type of information is irrelevant in this perspective, which in turn is critically important when considering that ITE has been demonstrated across trivia, opinion, and product written statements [9]. Therefore, enhanced processing fluency is experienced as a conflicting comparison standard and, in turn, the experienced conflict informs the truth judgment [10]. Consequently, evidence-based literature appears to support that increased exposure to information will lead to truth-rating inflation, thus influencing the statement's perceived credibility [11].

Interest in the underlying psychological mechanisms of decision-making, including those of jurors, has received increased interest over the past decade [12]. Without question, jurors are tasked with a civic responsibility of making difficult decisions in situations that can have serious implications for others. Therefore, it is imperative to have a clearer appreciation of the factors, including cognitive processes that impact their decision-making process. Developing a better appreciation of the cognitive processes behind jurors' decisions can help improve the fairness and effectiveness of the criminal justice system [13]. Considering the upsurge of interest in cognitive processing and decision-making in legal circles, the impact of ITE in juror deliberations seems apropos and timely as it has not yet been examined in this context.

While the ITE phenomenon is wellestablished [3], the current study sought to explore if the temporal order of evidentiary facts also has any effects in decision-making.

Neuropsychological research [14] continues to support a strong effect of information placement on learning and information recall patterns, namely primacy effects (information presented early in the narrative is better recalled) and recency effects (information presented later in the narrative is better recall). Whether there can be a greater influence imparted by a primacy effect or recency effect in legal decisionmaking is still being debated. To date, there have been mixed results about whether there is a stronger primacy effect in the context of decisionmaking [15] or not [16]. However, a study by Dennis and Ahn [17] held a firm position that critical information presented early (primacy effect) influenced participants' ability to draw causal relationships with respect to information that followed. Hence, timing in terms of when to introduce evidence may be important. 
In this study, we explored the impact of repeating certain critical facts in a criminal case on a naive sample of participants' decisionmaking toward important evidentiary facts (e.g., DNA evidence), as well as the implication of repeating the information at various points in the deliberative process. Firstly, if ITE holds, then participants will show a bias in weighing various components of the second-degree murder trial in the vignette. Secondly, according to Dennis and Ahn [17], ITE at the beginning of the summary of facts (primacy) should have more impact than any other placements within the narrative. Lastly, as mentioned above, we sought to determine whether ITE would also impact other important or case related details.

\section{Methods}

\section{Recruitment and Participants}

Participants were recruited from undergraduate students enrolled at McMaster University in Hamilton, Ontario, Canada, through SONA Systems. This online recruitment system allows students, primarily enrolled in an Introduction to Psychology course to receive credit for participation in psychology studies. Participants were granted 0.5 credits toward their final grade. In total, 100 participants completed the study, which took on average 30 minutes. Participants' ages ranged from 18 to 26 years old, with a median age of 18 . There were 84 female participants, 15 male participants, and one participant who preferred not to disclose. This study received ethical approval from McMaster Research Ethics Manager, project number 347 .

\section{Vignette Design}

Participants were asked to read an abbreviated version of an actual Canadian criminal case, R. v. Kionke, 2017. A summary of the case is provided [18] excluding the judge's final verdict to parallel what participants read in the vignette:

\section{Summary: R. v. Kionke}

On September 4, 2013, the bodies of Crow and Sinclair were found in their apartment on the third floor of a rooming house on Chestnut Street, in Winnipeg, Manitoba. Kionke lived in an apartment on the second floor. An autopsy performed on the bodies confirmed that Crow and Sinclair had died from multiple stab wounds, and due to the state of the bodies when they were discovered, the exact date of their death is unknown. On September 5th, 2013, Kionke and his girlfriend, Randall, were interviewed by investigators as potential witnesses. At this interview, Kionke and Randall both denied having knowledge of any information. In November 2013, after Randall's relationship with Kionke ceased, she returned to the police and updated her statement, admitting that Kionke had informed her to lie to the police during the original interview. In February 2014, Kionke was arrested and interrogated for a second time, while some details changed, he maintained his innocence. At trial, Kionke testified that Crow and Sinclair had stabbed each other and during the trial, Kionke stated a number of falsehoods and contradictions. Expert testimony also confirmed Kionke's DNA was found in multiple locations in Crow and Sinclair's apartment.

In this case, the accused, Kionke, was found guilty of second-degree murder of his neighbours. For this study, the case was modified and the judge's verdict, including commentary, was removed. The final modified vignette was seven pages long (about 3,600 words). Four experimental versions of the vignette were created. Participants were randomly assigned to one of four experimental conditions (Groups). Two key phrases were selected to emphasize the noncredibility of the accused (i.e., Kionke was an unreliable witness) and the gravity of the injuries (i.e., multiple stab wounds).

1. Group 1 served as the control condition in which no manipulation or repetition of the key phrases was present, so "multiple stab 
wounds" and "Kionke was an unreliable witness" remained intact as per the original case vignette.

2. Group 2 was used to assess the effect of ITE. As such, the key phrases "multiple stab wounds" and "Kionke was an unreliable witness" were evenly distributed throughout the entire vignette, repeated seven times each.

3. Group 3 was used to test the primacy effect, so the phrases "multiple stab wounds" and "Kionke was an unreliable witness" were each repeated seven times within the first half of the vignette.

4. Group 4 was used to test the recency effect, so participants were presented with a vignette containing the phrases "multiple stab wounds" and "Kionke was an unreliable witness" repeated seven times each within the last half of the vignette.

\section{Questionnaire Design}

A questionnaire was developed to assess the impact of the various manipulations described above. Participants were instructed to complete it after reading the vignette. The questionnaire contained 12 questions using a Likert-type scale, ranging from 1 Strongly Disagree to 7 Strongly Agree, to ascertain their level of agreement with the statement or question. The scale was reversed every alternating question to avoid a directional response bias (i.e., checking automatically the left or right side of the scale). The questionnaire had three questions of interest to measure the influence of ITE (i.e., 5, 6, and 10). As far as placement or primacy versus recency, three questions sampled facts found only at the beginning of the case (i.e., 1, 2, and 11 ) and three questions sampled facts found only at the end of the case (i.e., 4, 8, and 12). We also used a neutral space by asking three questions sampling facts in the middle of the case (i.e., 3, 7, and 9).

\section{Procedure}

After informed written consent was obtained, participants were presented with a paper version of a modified case vignette involving the criminal case and a questionnaire. Participants were instructed to read the vignette in its entirety before completing the questionnaire. After reading the vignette, the questionnaire was completed without making any further reference to the vignette. Participants were reminded at the outset that there was no time constraint, and they could spend longer than the 30 minutes allotted to complete the study, if necessary.

\section{Data Analysis}

To examine the influence of repetition (ITE), Kruskal-Wallis ANOVAs for nonparametric statistics were performed. A priori the following analyses were suggested to address the hypotheses generated by this study.

In test one, a whole ANOVA was planned to determine if any differences existed in terms of the responses provided to all 12 questions across all four groups.

In test two, we planned to highlight the potential impact of ITE; hence Group 1 (control) was to be compared to the experimental Groups 2, 3, and 4 (ITE). To examine the impact of the recency and primacy effects on jurors' decision-making, two additional Kruskal-Wallis ANOVAs for nonparametric statistics were proposed.

In test three, Group 2 was to be contrasted to Groups 3 (primacy) and 4 (recency) combined.

In the last test, Groups 3 (primacy) and 4 (recency) were compared to each other.

Before implementing the statistical approaches described above, descriptive statistics were performed on the whole sample across groups and questions to assess statistical characteristics (e.g., skewness) of the sample.

\section{Debriefing}

Following completion of the study, participants were presented with a debriefing form, which they were encouraged to read in the presence of the examiner. Any questions generated by the debriefing process were addressed by the examiner. As the vignette contained details 
pertaining to a second-degree murder trial that could be construed as disturbing to some after the completion of the study (i.e., after leaving the laboratory), each participant was also provided with the written resource contact information of the McMaster Student Wellness Centre, instructed to visit their family doctor, or instructed to visit the emergency department of their local hospital if they felt their well-being warranted it.

\section{Results}

Given the nature of the data, a nonparametric approach was suggested. However, after an initial sweep of the data (i.e., descriptive statistics), it was determined that the data was not skewed uniformly across all questions for the four groups, thus the use of a statistic like Kruskal-Wallis nonparametric ANOVA was not feasible. In response, the data was reformatted into a binary set. As such, the Likerttype scale was parcelled into disagree (values 1 through 3) and agree (values 5 through 7) responses. Responses that contained the neutral endorsement (value 4) were discarded from the analyses. We conducted appropriate chi-square analyses to determine if the null hypothesis (i.e., no effect of ITE) was challenged. Chi-square analyses were completed for each question. The following sections provide the outcome of the statistical analyses.

\section{ITE in General}

In the first set of analyses, the impact of ITE was explored. The three questions under review focused on specific evidentiary facts, namely the accused reliability as a witness, criminal responsibility, and the determination of guilt. The findings are as follows.

\section{Q5 Kionke is a reliable witness.}

The first question addressed the issue of reliability on the part of the accused. The first step
Table 1: ITE in general

Table 1a Distribution of agreement across groups on Q5 Kionke is a reliable witness.

\begin{tabular}{lccc} 
& \multicolumn{2}{c}{ Level of agreement, $\boldsymbol{n}(\%)$} & \\
\cline { 2 - 3 } Group & Disagree & Agree & Total \\
\hline Group 1, Control & $17(20.2)$ & $3(30.0)$ & $20(100)$ \\
Group 2, ITE & $22(26.2)$ & $3(30.0)$ & $25(100)$ \\
Group 3, ITE-Primacy & $21(25.0)$ & $3(30.0)$ & $24(100)$ \\
Group 4, ITE-Recency & $24(28.6)$ & $1(10.0)$ & $25(100)$ \\
Total & 84 & 10 & 94 \\
\hline
\end{tabular}

Table 1b Distribution of agreement across groups on Q6 Kionke is responsible for all of the victim's multiple stab wounds.

\begin{tabular}{lccc} 
& \multicolumn{2}{c}{ Level of agreement, $\boldsymbol{n}(\%)$} & \\
\cline { 2 - 3 } Group & Disagree & Agree & Total \\
\hline Group 1, Control & $14(63.6)$ & $8(36.4)$ & $22(100.0)$ \\
Group 2, ITE & $10(45.5)$ & $12(54.5)$ & $22(100.0)$ \\
Group 3, ITE-Primacy & $9(50.0)$ & $9(50.0)$ & $18(100.0)$ \\
Group 4, ITE-Recency & $6(33.3)$ & $12(66.7)$ & $18(100.0)$ \\
Total & 39 & 41 & 80 \\
\hline
\end{tabular}

Table 1c Distribution of agreement across groups on Q10 Kionke is guilty of the two murders.

\begin{tabular}{lccc} 
& \multicolumn{2}{c}{ Level of agreement, $\boldsymbol{n}(\%)$} & \\
\cline { 2 - 3 } Group & Disagree & Agree & Total \\
\hline Group 1, Control & $9(42.9)$ & $12(57.1)$ & $21(100.0)$ \\
Group 2, ITE & $5(31.3)$ & $11(68.7)$ & $16(100.0)$ \\
Group 3, ITE-Primacy & $8(44.4)$ & $10(55.6)$ & $18(100.0)$ \\
Group 4, ITE-Recency & $5(26.3)$ & $14(73.7)$ & $19(100.0)$ \\
Total & 27 & 47 & 74 \\
\hline
\end{tabular}

was to compare responses to Q5 across all four groups to determine if repetition of evidentiary fact (i.e., ITE) had an impact on this aspect of the accused. The findings were not significant. A visual inspection of Table 1a shows that respondents were uniformly in agreement across all group conditions; that is, the majority disagreed that Kionke was a reliable witness.

\section{Q6 Kionke is responsible for all of the victim's multiple stab wounds.}

The next question of interest, Q6, was directed at the issue of responsibility of the injuries 
Table 2: ITE primacy placement ${ }^{\mathrm{a}}$

Table 2a Distribution of agreement across groups on Q1 This case occurred in Winnipeg, Manitoba.

\begin{tabular}{lccc} 
& \multicolumn{2}{c}{ Level of agreement, $\boldsymbol{n}(\%)$} & \\
\cline { 2 - 3 } Group & Disagree & Agree & Total \\
\hline Group 2, ITE & $0(0.0)$ & $25(100.0)$ & $25(100.0)$ \\
Group 3, ITE-Primacy & $2(9.1)$ & $20(90.9)$ & $22(100.0)$ \\
Group 4, ITE-Recency & $1(4.0)$ & $24(96.0)$ & $25(100.0)$ \\
Total & 3 & 69 & 72 \\
\hline
\end{tabular}

Table $2 b$ Distribution of agreement across groups on Q2 The doctor who performed the autopsies, Dr. Balachandra was unable to pinpoint the deceased date of death due to their state of decomposition.

\begin{tabular}{lccc} 
& \multicolumn{2}{c}{ Level of agreement, $\boldsymbol{n}(\%)$} & \\
\cline { 2 - 3 } Group & Disagree & Agree & Total \\
\hline Group 2, ITE & $0(0.0)$ & $25(100.0)$ & $25(100.0)$ \\
Group 3, ITE-Primacy & $2(9.1)$ & $20(90.9)$ & $22(100.0)$ \\
Group 4, ITE-Recency & $1(4.0)$ & $24(96.0)$ & $25(100.0)$ \\
Total & 3 & 69 & 72 \\
\hline
\end{tabular}

Table 2c Distribution of agreement across groups on Q11 Kionke told a number of falsehoods to police about the events of the evening including that he cut his finger while cutting a loaf of frozen bread.

\begin{tabular}{lccc} 
& \multicolumn{2}{c}{ Level of agreement, $\boldsymbol{n}(\%)$} & \\
\cline { 2 - 3 } Group & Disagree & Agree & Total \\
\hline Group 2, ITE & $3(12.5)$ & $21(87.5)$ & $24(100.0)$ \\
Group 3, ITE-Primacy & $1(4.2)$ & $23(95.8)$ & $24(100.0)$ \\
Group 4, ITE-Recency & $1(4.2)$ & $23(95.8)$ & $24(100.0)$ \\
Total & 5 & 67 & 72 \\
\hline
\end{tabular}

a Because Group 1, control, did not include ITC, it is not included in this analysis.

inflicted on the victims. Again, the overall analysis was unyielding, meaning no overall significant effects. However, a closer look at the data found in Table $1 \mathrm{~b}$ suggests that the level of agreement between Group 1 (the control group) and Group 4 (ITE-recency) differed, which was supported by a planned contrast between the two $(\mathrm{LR}=3.9, d f=1, p=.05)$. Thus, presenting the repeated information at the end of the narrative swayed the respondent about their level of agreement of Kionke's responsibility in the victims' fatal injuries.

\section{Q10 Kionke is guilty of the two murders.}

The next question, Q10, was about culpability. A visual inspection of Table 1c shows that the majority of respondents felt that Kionke was guilty. Additionally, repetition (ITE) did not influence their views in a significant manner, albeit it is noteworthy that Group 1 (the control group) $(42.9 \%$ vs. $57.1 \%)$ appeared mixed in their determination, when compared with the Group 2 (ITE) (31\% vs. $69 \%$ ) and Group 4 (ITE-recency) (26.3\% vs. $73.7 \%)$. Hence repeating key phrases increased participants' confidence that Kionke is guilty by a factor of two to three.

Overall, the findings generated by the three questions reviewed above support a role for ITE under specific conditions, namely the questions addressing issues of responsibility for the wounds inflicted (Q6) and to a similar degree, albeit not statistically significant, on the issue of guilt (Q10).

\section{ITE Primacy}

In the next set of analyses, the influence of primacy and recency effects was assessed. Thus, participants' response pattern (agree or disagree) to questions sampling various parts of the vignette was examined under conditions where the key phrases addressing the stab wounds and reliability of Kionke was either offered early (primacy) or late (recency) in the narrative. The first set of analyses investigated the impact of ITE early in the case narrative. The three questions under review focused on specific evidentiary facts, namely the location of offence, time of death, and the accused reported injuries. The findings are as follows.

\section{Q1 This case occurred in Winnipeg, Manitoba.}

Table 2a shows the results from participants' agreement with information that was presented 
early in the narrative. In this case, where the murders occurred (Q1). Here the influence of ITE did not vary in a significant manner across Group 2 (ITE) or localized distribution of fact found in Group 3 (ITE-primacy) and Group 4 (ITE-recency). A closer look at Table 2a supports that overwhelmingly participants were confident (agree) about the fact that the murders occurred in Winnipeg. Moreover, the planned (ITE-primacy vs. ITE-recency) contrast, as expected, did not yield any significant findings.

Q2 The doctor who performed the autopsies, Dr. Balachandra, was unable to pinpoint the victim's date of death due to their state of decomposition.

Table 2b shows participants' appraisal of the coroner's difficulty pinpointing the actual time of death for the deceased. Here ITE did not vary in a significant manner based on widespread dissemination of fact repetition (Group 2, ITE) or localized distribution of fact (Group 3, ITEprimacy and Group 4, ITE-recency). A closer look at Table $2 b$ supports that a large percentage of individuals across all groups were confident about the coroner's struggles to pinpoint the time of death regardless of placement of ITE.

\section{Q11 Kionke told a number of falsehoods} to police about the events of the evening including that he cut his finger while cutting a loaf of frozen bread.

Table 2c shows the result from the respondents' appraisal of Kionke's explanation for the origin of his injury. Here ITE did not vary in a significant manner based on widespread dissemination of fact repetition (Group 2, ITE) or localized distribution of fact (Group 3, ITE-primacy and Group 4, ITErecency). A closer look at Table 2c supports that a large percentage of individuals were confident about Kionke's attempts to deceive, regardless of placement of ITE. Hence, the overall (omnibus) or planned (ITE vs. ITEprimacy or ITE-recency) contrast did not yield any significant findings.

\section{ITE Recency}

The next set of analyses investigated the impact of ITE on narrative of evidentiary facts presented late in the vignette. The three questions under review focused on specific evidentiary facts, namely the presence of DNA on the weapon, getting rid of evidence, and DNA from a third person located at the scene. The findings are as follows.

\section{Q4 Kionke's DNA was found on a piece of copper piping outside of the victim's apartment from a passive blood stain.}

As seen in Table 3a, the pattern of responses was fairly similar across groups with the exception of Group 4 (ITE-recency) that, on cursory look, displayed a stronger shift in the level of agreement. As expected, the overall analysis did not support immediate difference in widespread dissemination of fact repetition (Group 2, ITE) or localized distribution of fact (Group 3, ITE-primacy and Group 4, ITErecency). However, as indicated above, Group 4 (ITE-recency) appeared to separate themselves from the other two groups in their level of confidence about the information under consideration. Hence, a marginally significant result is noted when comparing Group 2, ITE, with Group 4, ITE-recency $(\mathrm{LR}=3.47, d f=1$, $p=.06)$.

Q8 Following the event, Kionke left the victims' apartment and showered with his clothes on to remove the blood and change into different clothes.

Table 3b presents the results from participants' appraisal of Kionke's behaviour to conceal any evidence of blood. Here ITE did not vary in a significant manner based on widespread dissemination of fact repetition (Group 2, ITE) or localized distribution of fact (Group 3, ITEprimacy, and Group 4, ITE-recency). A closer look at Table $3 b$ supports that a large percentage of individuals were confident about Kionke's attempts to deceive regardless of placement of ITE. Hence, the overall (omnibus) or planned (ITE vs. ITE-primacy or ITE-recency) contrast did not yield any significant findings. 
Table 3: ITE recency placement ${ }^{\mathrm{a}}$

Table 3a Distribution of agreement across groups on Q4 Kionke's DNA was found on a piece of copper piping outside of the victim's apartment from a passive blood stain.

\begin{tabular}{lccc} 
& \multicolumn{2}{c}{ Level of agreement, $\boldsymbol{n}(\%)$} & \\
\cline { 2 - 3 } Group & Disagree & Agree & Total \\
\hline Group 2, ITE & $5(20.8)$ & $19(79.2)$ & $24(100.0)$ \\
Group 3, ITE-Primacy & $3(12.0)$ & $22(88.0)$ & $25(100.0)$ \\
Groups 4, ITE-Recency & $1(4.0)$ & $24(96.0)$ & $25(100.0)$ \\
Total & 9 & 87 & 96 \\
\hline
\end{tabular}

Table 3b Distribution of agreement across groups on Q8 Following the event, Kionke left the victims apartment and showered with his clothes on to remove the blood and change into different clothes.

\begin{tabular}{lccc} 
& \multicolumn{2}{c}{ Level of agreement, $\boldsymbol{n}(\%)$} & \\
\cline { 2 - 3 } Group & Disagree & Agree & Total \\
\hline Group 2, ITE & $4(16.0)$ & $21(84.0)$ & $25(100.0)$ \\
Group 3, ITE-Primacy & $6(24.0)$ & $19(76.0)$ & $25(100.0)$ \\
Group 4, ITE-Recency & $3(12.0)$ & $22(88.0)$ & $25(100.0)$ \\
Total & 13 & 62 & 75 \\
\hline
\end{tabular}

Table 3c Distribution of agreement across groups on Q12 Some of the DNA found in the swab taken was from an unidentified male known as Male 3.

\begin{tabular}{lccc} 
& \multicolumn{2}{c}{ Level of agreement, $\boldsymbol{n}(\%)$} & \\
\cline { 2 - 3 } Group & Disagree & Agree & Total \\
\hline Group 2, ITE & $5(25.0)$ & $15(75.0)$ & $20(100.0)$ \\
Group 3, ITE-Primacy & $3(13.0)$ & $20(87.0)$ & $23(100.0)$ \\
Group 4, ITE-Recency & $4(16.0)$ & $21(84.0)$ & $25(100.0)$ \\
Total & 12 & 56 & 68 \\
\hline
\end{tabular}

a Because Group 1, control, did not include ITC, it is not included in this analysis.

\section{Q12 Some of the DNA found in the swab} taken was from an unidentified male known as Male 3.

Table 3c presents the pattern of responses to the DNA findings. As expected, the overall analysis did not support immediate difference in widespread dissemination of fact repetition (Group 2, ITE) or localized distribution of fact (Group 3, ITE-primacy, and Group 4, ITErecency). However, as indicated above,
Group 4 (ITE-recency) appeared to separate themselves, albeit ever so slightly, from the other two in their level of confidence about the information being considered. Hence, a marginally significant result is noted when comparing Group 2 (ITE) with Group 4 (ITE-recency) (LR $=3.47$, $d f=1, p=.07$ ).

\section{ITE Middle}

We include another position to the examination, adding questions sampling facts from the middle of the case. We wondered if strategic repetition of key phrases would have any impact on participants' processing of the questions about information located in this sector of the narrative. The findings presented by Dennis and Ahn [17] support greater primacy effects on evaluation of pertinent information. As such, the reasoning was that information presented in the middle would possibly be preferentially influenced by primacy effect. The three questions under review focused on specific evidentiary facts, namely the location of a potential accomplice, arrest location, and the possibility of obstructing justice. The findings are as follows.

\section{Q3 Kionke's girlfriend testified that} on the evening of the crime she was with her son getting ice caps.

Table $4 a$ shows the results from participants' appraisal of Kionke's girlfriend's behaviour on the night of the offence. Here ITE did not vary in a significant manner based on widespread dissemination of fact repetition (Group 2, ITE) or localized distribution of fact (Group 3, ITEprimacy, and Group 4, ITE-recency). A closer look at Table $4 a$ supports that a large percentage of individuals were confident (agree) about Kionke's girlfriend's whereabouts that night. Hence, the overall or planned (ITE vs. ITE-primacy or ITE-recency) contrast did not yield any significant findings. 
Q7 Kionke was arrested in Regina, Saskatchewan, in February of 2014 and brought in for questioning.

Table $4 \mathrm{~b}$ presents the location of the arrest. As expected, the overall analysis did not support immediate difference in widespread dissemination of fact repetition (Group 2, ITE) or localized distribution of fact (Group 3, ITE-primacy, and Group 4, ITE- recency). However, Group 3 appeared to separate themselves, albeit ever so slightly, from the other two groups in their level of confidence about the information being considered. Hence, a significant result is noted comparing Group 2 (ITE) from Group 3 (ITE- primacy) (LR = 3.99, $d f=$ $1, p=.04)$, while none is seen between primacy and recency groups.

\section{Q9 Kionke's girlfriend at the time} knew about the event and did not tell police.

In Table 4c, participants weighed in on their belief of Kionke's girlfriend's knowledge of the event. Here in the middle position, this type of information did not appear to move the respondent's level of agreement across the three ITE conditions. In fact, ITE did not vary in a significant manner based on widespread dissemination of fact repetition (Group 2, ITE) or localized distribution of fact (Group 3, ITE- primacy, and Group 4, ITE-recency). A closer look at Table 4c supports that respondents were almost split in half about their agreement on the girlfriend's knowledge of the events. Hence, the overall or planned (ITE vs. ITE- primacy or ITE-recency) contrast did not yield any significant findings.

The findings above provide limited evidence that information sampled in the middle of the narrative was influenced by the placement of repeated key phrases (ITE), in this case at the beginning of the vignette.
Table 4: ITE middle placement ${ }^{\mathrm{a}}$

Table 4a Distribution of agreement across groups on Q3 Kionke's girlfriend testified that on the evening of the crime she was with her son getting ice caps.

\begin{tabular}{lccc} 
& \multicolumn{2}{c}{ Level of agreement, $\boldsymbol{n}(\%)$} & \\
\cline { 2 - 3 } Group & Disagree & Agree & Total \\
\hline Group 2, ITE & $3(25.0)$ & $21(75.0)$ & $24(100.0)$ \\
Group 3, ITE-Primacy & $0(0)$ & $22(100.0)$ & $22(100.0)$ \\
Group 4, ITE-Recency & $1(16.0)$ & $23(84.0)$ & $24(100.0)$ \\
Total & 4 & 66 & 70 \\
\hline
\end{tabular}

Table 4b Distribution of agreement across groups on Q7 Kionke was arrested in Regina, Saskatchewan, in February of 2014 and brought in for questioning.

\begin{tabular}{lccc} 
& \multicolumn{2}{c}{ Level of agreement, $\boldsymbol{n}(\%)$} & \\
\cline { 2 - 3 } Group & Disagree & Agree & Total \\
\hline Group 2, ITE & $10(58.8)$ & $7(41.2)$ & $17(100.0)$ \\
Group 3, ITE-Primacy & $6(27.3)$ & $16(72.7)$ & $22(100.0)$ \\
Group 4, ITE-Recency & $8(34.8)$ & $15(65.2)$ & $23(100.0)$ \\
Total & 24 & 38 & 62 \\
\hline
\end{tabular}

Table 4c Distribution of agreement across groups on Q9 Kionke's girlfriend at the time knew about the event and did not tell police.

\begin{tabular}{lccc} 
& \multicolumn{2}{c}{ Level of agreement, $\boldsymbol{n}(\%)$} & \\
\cline { 2 - 3 } Group & Disagree & Agree & Total \\
\hline Group 2, ITE & $10(41.7)$ & $14(58.3)$ & $24(100.0)$ \\
Group 3, ITE-Primacy & $9(40.9)$ & $13(59.1)$ & $22(100.0)$ \\
Group 4, ITE-Recency & $13(54.2)$ & $11(45.8)$ & $24(100.0)$ \\
Total & 32 & 38 & 70 \\
\hline
\end{tabular}

a Because Group 1, control, did not include ITE, it is not included in this analysis.

\section{Discussion}

The purpose of this study was to explore if repetition and placement of evidentiary information influenced jurors' perceptions of a case. The findings support an effect of information manipulation, namely ITE and its placement within the vignette, on participants' appraisal of various questions related to a charge of second-degree murder. Our findings are discussed below in the context of the current literature and possible implications for juror deliberations. 


\section{ITE in General}

The impact of ITE, without reference to placement, focused on the reliability, credibility, and criminal responsibility of the accused. The analysis supported a significant finding on the question of responsibility for the victim's injuries (Q6), as the level of agreement was statistically influenced by the repetition of the key phases. As it pertained to Kionke's reliability as a witness, the entire sample of participants agreed he was culpable of the offence regardless of group assignment. Hence, this study suggested that the impact of ITE may be critical when individuals such as jurors are asked to attribute weight to pertinent legal evidence. It has been well documented that repeated information of an ambiguous statement increases the probability it will be deemed true [10]. This notion has been shown to hold in many different contexts; however, this study is the first to demonstrate that ITE could be relevant in the context of legal decision-making.

Moreover, these findings suggest that the manner in which information is presented, namely repetition of critical evidence, may hold increased salience with respect to its pe suasive nature. In the courtroom, an expert's testimony is frequently challenged during cross-examination by using strategies or tactics to discredit the information provided. As well, evidence-based literature supports that where expert testimony is provided, jurors become more skeptical of nonexpert testimony, thus ensuring the need to consider the weight and source of the legal evidence presented [19]. The ITE findings in this study support the position that repetition of key evidence will further influence jurors' perception of facts, as illustrated by the comparison of Group 1 (the control) and ITE groups in Q6 (responsibility) and Q10 (guilt).

\section{ITE Placement}

Findings generated by this study suggest that the placement of key phrases influences participants' perceptions of legal case material. The design of our study linked repetition of key phrases and location of evidence surveyed by targeted questions. As such, when ITE was at the beginning of the vignette, we sampled evidence located in that section of the case (primacy), and vice versa at the end of the case (recency). Information provided at the beginning (primacy) did not appear to greatly impact participants, as reflected by consistent responding across group assignments about where the murder occurred, the fact that the coroner could not reliably establish time of death, or that Kionke falsely disclosed that he cut his finger while slicing a frozen loaf of bread.

In contrast, clustering information (ITE) at the end (recency) seems to be more relevant and pertinent for deliberation of evidentiary facts. This was particularly evident with respect to DNA evidence, as illustrated by participants' responses to the questions addressing the presence of a third party via DNA (Q12) and that Kionke's DNA was found at the location of the crime (Q4). Previous literature was mixed as to whether a primacy effect exists or not $[16,17]$. However, in their persuasion study examining primacy and recency effects, Miller and Campbell [20] found that a recency effect is noticeable when there is a delay between communicated arguments. Although there is no control over timing effects of communicated arguments (i.e., no delays), a stronger recency effect than primacy effect was demonstrated, more so pertaining to critical evidence such as DNA findings. A single primacy effect was found in relation to the arrest (i.e., nonexpert evidence). Thus, it appears that pertinent information presented later in the stream of factual evidence is an important factor in a juror's decision-making.

An additional and unanticipated finding generated by the questions addressing the issue of DNA (Q4 and Q12) highlighted that the nature or characteristic of the critical evidence matters in the decision-making process, especially when it was contrasted with the question that dealt with Kionke washing blood off his clothes (Q8). Thus, the nature (or characteristic) of the evidence may also be germane in influencing how jurors make their decisions. Gigerenzer and Gaissma [6] demonstrated the importance of salience noting that if one option is recognized 
faster than another, it is given a high value in decision-making, and repetition increases the ease in which individuals understand statements [6]. Questions addressing the DNA (Q4 and Q12) were evidence-based questions (i.e., facts supported by science), whereas the question about Kionke washing his clothes (Q8) was more of a nonexpert related question. It has been well documented that lay individuals have a high degree of confidence in the accuracy and reliability of DNA testing [21]. These results suggest that perhaps placement is not affected by opinion, but salience and perceived robustness of facts, as demonstrated by DNA evidence holding greater weight in participants' decisionmaking. This could be an additional important factor in the understanding of ITE during legal decision-making; that is, it may not just be the repetition of key information, but it is the association to critical (scientifically credible) evidence that is noteworthy. The findings from this study suggest that repetition of more reliable evidence, such as DNA evidence, whether accurate or not, could influence an individual's perceptions of its trustworthiness. Whereas previous research supports the impact of persuasion [2], our findings indicate that the mechanism underlying persuasiveness may be impacted by ITE and placement of critical evidence. More research is required to examine this relationship.

\section{Conclusion}

This study provided evidence that repeating (ITE) certain types of details, like the unreliability of an accused and gravity of injuries inflicted on victims, mattered in a potential juror's decision-making process. Other important evidentiary facts, such as DNA evidence, may also be impacted by the repetition (ITE), particularly when that information is presented toward the end of a trial.

\section{Limitations}

This research was conducted in a laboratory within a university setting and therefore not comparable with a real trial and jury environment. Each participant was presented with the same vignette and questionnaire, then invited to share their opinion individually. As such, this study had a lower level of ecological validity compared with the real conditions a jury would experience through the key process of group deliberation. Additionally, in a courtroom, a jury consists of a collective group that deliberates as a group to reach a verdict after the presentation of evidence in court. Moreover, a jury would typically receive specific instructions from a judge before deliberations. Hence, the lack of judiciary direction and group discussion limits this study's generalizability to some extent. Furthermore, participants read the information in the form of a case vignette, which is not comparable to how events unfold in an actual criminal trial. The participants in this study read a case vignette and critical information from one source, a legal case. In a real criminal trial, information would otherwise be presented by many witnesses; therefore, jurors can not only listen to and weigh the information before deliberating, but they can also see the witnesses as they testify. In a reallife setting, jurors' decisions can be influenced by nonverbal body language that occurs in the courtroom, which could not be replicated in this study.

We recognize that the context, individuality, and single source of information provided to participants in this study placed some limitations on the overall generalizability of the results. However, as shown here, ITE and placement appears to influence individual's deliberation process, which in a real-life context of deliberation has the potential to also impact the larger group (i.e., normative social influence). Notwithstanding, these effects merit further inquiry, including the aforementioned considerations.

In this study, the sample was drawn from a restricted pool of potential participants, which is not representative of all potential jury-pool members at large. Jury members can range in age, geographical location, and education, and typically are selected strategically by lawyers. Our sample was fairly homogenous, mainly comprised of undergraduate students enrolled in this study, all pursuing the same level of education and within a similar age group. 
Also, the composition of questions is a matter of review. Although the intent was to repeat critical information either throughout or in select areas of the case, more attention is needed to balance factors that may inadvertently bias the juror. For example, in future studies, it would be important to assure that placement and repetition is balanced in terms of relevance across importance of evidentiary information. These efforts would help distinguish between the impact of placement and repetition versus the nature of the information itself in the deliberation process. The need to eliminate possible confounds of opinion and evidence-based inquiry across the entire narrative of the case vignette is also critical in this process. It would be important to investigate the impact of ITE on erroneous information that may sway a potential juror from a guilty to non-guilty verdict, or vice versa.

\section{Future Studies}

Despite the limitations above, this is the first study to look at the ITE and evidentiary information placement in the context of juror decision-making. Hence, this study provides a basis for future studies to examine the influence of repetition and placement of critical evidence within a courtroom setting. As previously discussed, this study could be repeated using a mock-jury setting; hearing the evidence as opposed to reading it; including a more diverse participant demographic group rather than undergraduate students; and allowing participants to collectively deliberate over evidence presented from both defence and prosecution before making their final decision. In implementing these suggestions in future research, the impact of ITE and placement of evidentiary information could be assessed in a more ecologically valid manner. As such, we feel these findings have merit and provide a starting point to examine these other considerations about the potential impact of ITE and placement of critical information in jury deliberations.

\section{Conflict of Interest: none}

\section{References}

1. Gold V. Psychological manipulation in the courtroom. Nebraska Law Review. 1987;66(3):563-583. https://digitalcommons. unl.edu/nlr/vol66/iss3/11/.

2. Tanford S, Penrod S. Jury deliberations: Discussion content and influence processes in jury decision making. Journal of Applied Social Psychology. 1986;16(4):322-347. https://doi.org/10.1111/j.1559-1816.1986. tb01144.x.

3. Hasher L, Goldstein D, Roppino T. Frequency and the conference of referential validity. Journal of Verbal Learning and Verbal Behavior. 1977;16(1);107-112. https://doi.org/10.1016/S00225371(77)80012-1.

4. Wang W, Brashier N, Wing E, Marsh E, Cabeza R. On known unknowns: Fluency and the neural mechanisms of illusory truth. Journal of Cognitive Neuroscience. 2016;28(5):739-746. https://doi.org/10.1162/jocn_a_00923.

5. Fazio L, Brashier N, Payne B, Marsh E. Knowledge does not protect against illusory truth. Journal of Experimental Psychology: General. 2015;144(5):993-1002. https://doi.org/10.1037/xge0000098.

6. Gigerenzer G, Gaissmaier W. Heuristic decision making. The Annual Review of Psychology. 2011;62:451-82. https://doi. org/10.1146/annurev-psych-120709-145346.

7. Unkelbach C, Rom S. A referential theory of the repetition-induced truth effect. Cognition. 2017; 160:110-126.

https://doi.org/10.1016/j.cognition.2016.12.016.

8. DiFonzo N, Beckstead J, Stupak N, Walders $\mathrm{K}$. Validity judgments of rumors heard multiple times: The shape of the truth effect. Social Influence. 2016;11(1):22-39. https:// doi.org/10.1080/15534510.2015.1137224.

9. Oppenheimer D.M. The secret life of fluency. Trends in Cognitive Sciences. 2008;12(6):237-241. https://doi.org/10.1016/j.tics.2008.02.014.

10. Dechêne A, Stahl C, Hansen J, Wänke M. The truth about the truth: A meta-analytic review of the truth effect. Personality and Social Psychology Review. 2009;14(2):238-257. https://doi.org/10.1177/1088868309352251. 
11. Henkel L, Mattson M. Reading is believing: The truth effect and source credibility. Consciousness and Cognition. 2011;20(4):1705-1721. https://doi.org/10.1016/j.concog.2011.08.018.

12. Belcher A, Sinnott-Armstrong W. Neurolaw. Wiley Interdisciplinary Reviews. Cognitive Science. 2009;1(1):18-22. https://doi.org/10.1002/wcs.8.

13. Jones O, Marois R, Farah M, Greely H. Law and neuroscience. The Journal of Neuroscience. 2013;33(45):1762417630. https://doi.org/10.1523/ JNEUROSCI.3254-13.2013.

14. Morrison AB, Conway ARA, Chein JM. Primacy and recency effects as indices of the focus of attention. Frontiers in Human Neuroscience. 2014;24:1-14. https://doi.org/10.3389/fnhum.2014.00006.

15. Highhouse S, Gallo A. Order effects in personnel decision making. Human Performance. 1997;10(1):31-46. https://doi.org/10.1207/s15327043hup1001_2.

16. Marsh J, Ahn W. Order effects in contingency learning: The role of task complexity. Memory \& Cognition. 2006;34(3):568-576. https://doi.org/10.3758/BF03193580.

17. Dennis M, Ahn W. Primacy in causal strength judgments: The effect of initial evidence for generative versus inhibitory relationships. Memory \& Cognition. 2001;29(1):152-164. https://doi.org/10.3758/BF03195749.

18. R. v. Kionke, $2017 \mathrm{MBQB} 60$ (CanLII). https://www.canlii.org/en/mb/mbqb/ doc/2017/2017mbqb60/2017mbqb60.html.

19. Leippe M, Eisenstadt D, Rauch S, Seib H. Timing of eyewitness expert testimony, jurors' need for cognition, and case strength as determinants of trial verdicts. Journal of Applied Psychology. 2004;89(3):524-541. https://doi.org/10.1037/0021-9010.89.3.524.

20. Miller N, Campbell D. Recency and primacy in persuasion as a function of the timing of speeches and measurements. Journal of Abnormal and Social Psychology. 1959;59(1):1-9. https://doi.org/10.1037/h0049330.

21. Brewer P, Ley B. Media use and public perceptions of DNA evidence. Science Communication. 2009;32(1):93-117. https://doi.org/10.1177/1075547009340343.

\section{Corresponding author}

Bruno Losier, St. Joseph's Healthcare Hamilton, 100 West 5th Street, Hamilton, ON L9C 0E3, Canada; 905-522-1155 ext. 39357 - email: losierb@stjoes.ca 